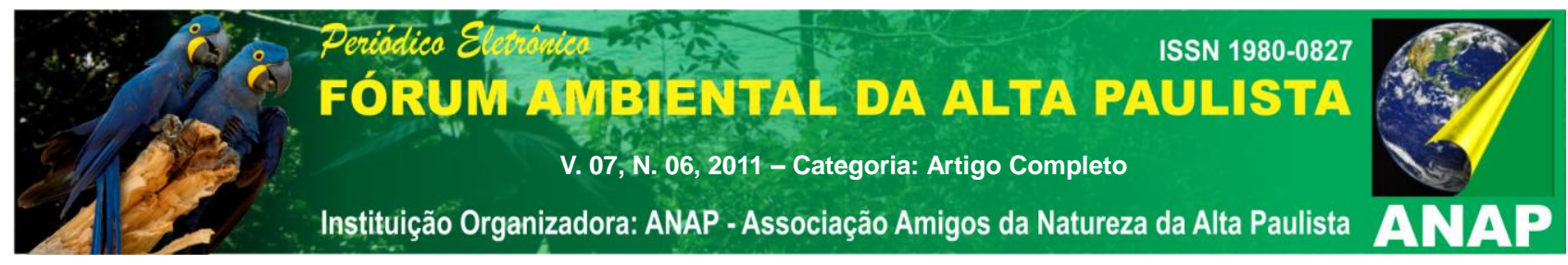

\title{
CONSERVAÇÃO DE RECURSO HÍDRICO E PERCEPÇÃO AMBIENTAL DOS MORADORES RIBEIRINHOS DA ÁREA URBANA DO MUNICÍPIO DE ARAGUATINS-TO.
}

\author{
Juliana Barros Carvalho ${ }^{1}$ \\ Deuzilane Do Carmo Xavier ${ }^{2}$ \\ Gabriel Leda Arruda ${ }^{3}$
}

\begin{abstract}
RESUMO: Esta pesquisa objetiva estudar a percepção e relações ambientais dos moradores que residem nas proximidades das margens do rio Taquari, com relação aos problemas ambientais e como tais problemas são observados e tratados pelos próprios moradores, compreendendo qual a importância que os moradores atribuem ao recurso hídrico, se há ou não interesse na sua conservação. Foram realizadas pesquisas de campo exploratória quantitativa e qualitativa. Para a captação dos dados usou-se como ferramenta de pesquisa um questionário. O rio no município é um importante recurso para a vida das comunidades biológicas locais, e infelizmente na área urbana pela aglomeração de pessoas há uma imensa degradação em suas margens, sua extensão no território urbano está bastante comprometida. $\mathrm{A}$ comunidade tem se preocupado com a situação atual do recurso natural, e o futuro das próximas gerações. A maioria não exercita a prática de conservação do meio ambiente por falta de conhecimento. Espera-se que o contato com a realidade deles, contribuirá para a reconstrução de conhecimentos, possibilitando a percepção de novos valores diante da relação ser humano/ambiente.
\end{abstract}

Palavras-chave: Percepção, Conservação, Taquari.

\section{INTRODUÇÃO}

A sociedade atual tem observado a importância de um bom relacionamento do homem com o ambiente, a temática ambiental está se tornando um assunto comum e prioritário, contudo, a correta percepção não está evidente, pois, de um lado os homens afirmam que o ambiente é importante, que é necessário preservar os recursos naturais 


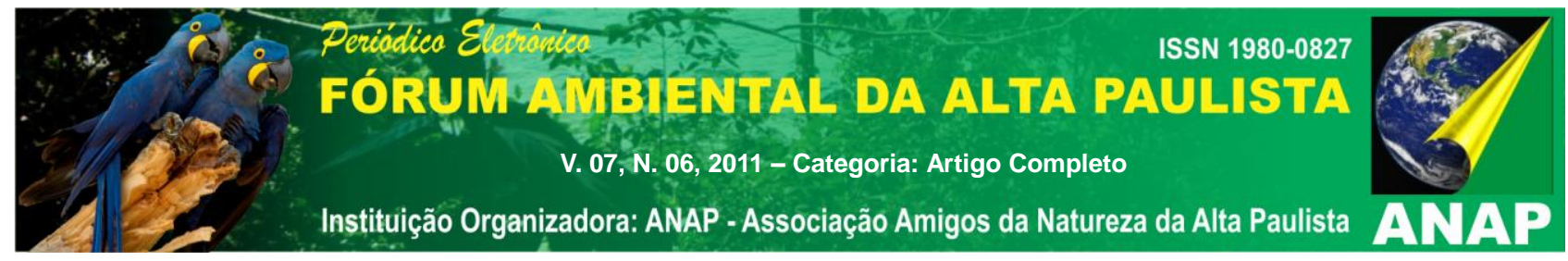

para as futuras gerações, e do outro lado as populações humanas degradam o que têm de mais precioso.

Percepção ambiental pode ser definida como sendo uma tomada de consciência do ambiente pelo homem, ou seja, o ato de perceber o ambiente que se está inserido, aprendendo a conviver com ele de maneira harmoniosa.

Conhecer a percepção ambiental da população é de fundamental importância para o planejamento de políticas ambientais; esta temática foi ressaltada pela UNESCO em 1973. Considerando que o modo de perceber e se relacionar com o ambiente pode variar de acordo com a cultura e grupo socioeconômico.

O nível de percepção, indubitavelmente, conduz o homem à um nível de conscientização ecológica que realça sua responsabilidade de conservação da natureza, como requisito de manutenção da sobrevivência humana, ou seja, o grau de percepção e o nível de conscientização pode ser considerados como pré requisitos de uma efetiva conservação da natureza (Macedo, 2000).

"A educação ambiental é um processo permanente nos quais os indivíduos tomam consciência do seu meio ambiente e adquirem valores, habilidades e experiências que os tornem aptos a agir e resolver problemas ambientais presentes e futuro" ( STRANZ, 2002, p.230).

O Brasil possui recursos hídricos renováveis de expressão mundial. O uso multifuncional dos rios implica em manejo cuidadoso a ser realizado de maneira sustentável e satisfatória a todos os interessados (HOUSE, 1999). Portanto, os rios podem ser valiosos temas de projetos de educação ambiental, uma vez que a participação pública em manejo de bacias hidrográficas pode realmente contribuir para 0 seu sucesso. (HOUSE, op. Cit.).

O município de Araguatins-TO é banhado pelo rio Araguaia e pelo rio Taquari, que tem $40 \mathrm{~km}$ de extensão, aproximadamente, sendo afluente do primeiro. Têm suas nascentes localizadas parte no município de Axixá e parte no povoado Boa Sorte. Desemboca no perímetro urbano de Araguatins. A aglomeração urbana do município localiza-se à margem direita do rio, que representa um importante recurso hídrico para a população. Essa aglomeração humana às margens do rio Taquari representa um enorme ameaça ao recurso hídrico, pois o mesmo atravessa o perímetro urbano. 


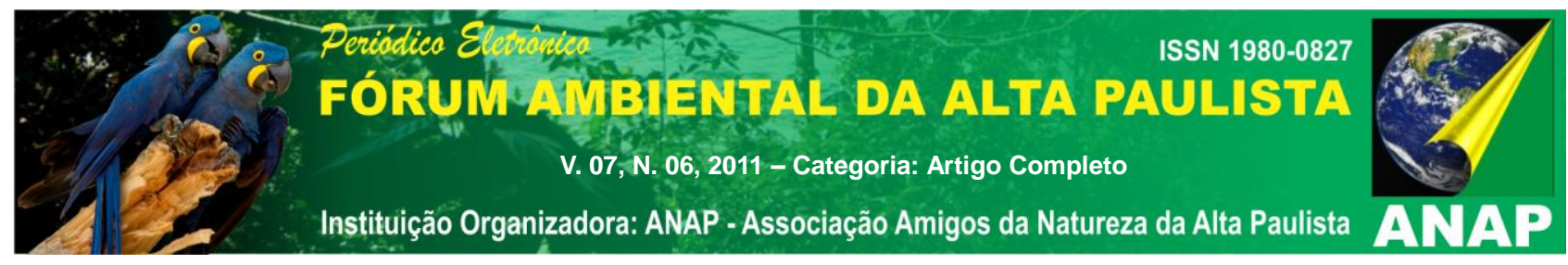

Esta bacia vem sendo palco de intensas transformações impulsionadas pela política de desenvolvimento Estadual através da construção de rodovias, instalação de grandes projetos agrícolas. Dessa forma, vem sofrendo inúmeras agressões, como: desmatamento de matas ciliares, poluição de recursos hídricos; crescimento desordenado da população e ocupação de áreas sem planejamento; agropecuária intensiva e uso descomedido de água; fatos que podem comprometer o abastecimento das áreas urbanas da cidade, ocasionando problemas de saúde pública, socioeconômicos (CARVALHO, et al,2006, p.117).

Conhecer a percepção e relações ambientais dos moradores das comunidades ribeirinhas do rio Taquari é primordial no desenvolvimento de políticas para o uso sustentável desse recurso hídrico. Segundo FERNANDES, et al,(2004, p 2) a educação e percepção ambiental despontam como armas na defesa do meio natural, e ajuda a reaproximar o homem da natureza, garantindo um futuro com mais qualidade de vida para todos, já que desperta uma maior responsabilidade e respeito dos indivíduos em relação ao meio em que vivem.

\section{DESENVOLVIMENTO}

\subsection{METODOLOGIA}

O campo de pesquisa escolhido foi as áreas próximas às margens do rio Taquari no perímetro urbano do município de Araguatins-TO.

O município de Araguatins localiza-se no extremo norte do Estado do Tocantins, na microrregião do Bico do Papagaio, a $660 \mathrm{~km}$ de Palmas. Apresenta população de baixa renda, a maior fonte econômica do município é a agricultura e pecuária. $O$ rio Taquari esta localizado em uma área de transição entre floresta amazônica e cerrado. A temperatura média varia de $24^{\circ}$ a $30^{\circ}$, a temperatura mais elevada ocorre em julho e setembro com as realizações de queimadas na região chegando a $38^{\circ} \mathrm{C}$. O maior índice pluviométrico acontece de novembro a maio.

Para alcançar os objetivos propostos na presente pesquisa, optou-se pelo desenvolvimento de uma pesquisa de campo exploratória quantitativa e qualitativa.

Inicialmente realizou-se um levantamento bibliográfico de livros, artigos científicos, pesquisa na internet, documentos municipais, entre outros. Objetivando conhecer sobre a temática ambiental a nível global e regional. 


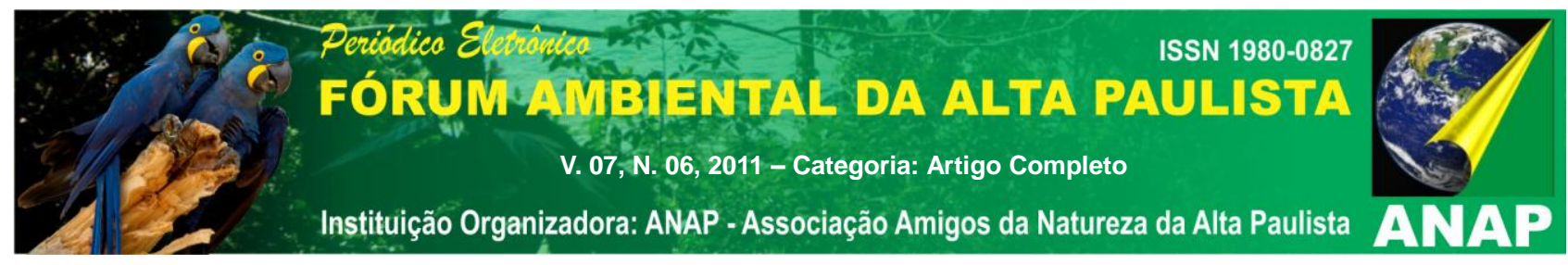

Foram realizadas visitas na localidade escolhida para a pesquisa com o intuito de conhecer o campo de pesquisa, ter contato com a população ribeirinha, para fazer o levantamento da quantidade de pessoas que estão diretamente ligadas ao rio, traçar o perfil sociocultural do público alvo, para servir de base na elaboração dos questionários, que precisou ter uma linguagem acessível à todos os entrevistados, sem perder o foco da pesquisa. Houve também diálogo com a população, ouvindo-os sobre o seu convívio com o rio e esclarecendo quanto ao objetivo da pesquisa.

O questionário foi composto por 18 questões, do tipo fechada, aberta e mista, a consciência ambiental da população foi avaliada nas diferentes questões, com ênfase nos problemas ambientais.

Dividido nas seguintes etapas:

- Perfil dos entrevistados;

- Conscientização ambiental;

- Percepção sobre o rio Taquari

$\mathrm{Na}$ área urbana foram aplicados os questionários nas residências dos moradores das proximidades das margens do rio com população estimada de 350 pessoas, dessas 105 responderam ao questionário. A quantidade de pessoas nas famílias ribeirinhas foi calculada com base em estimativas do IBGE, que conta aproximadamente 4 pessoas por residência.

Escolhemos para a pesquisa o método estatístico descritivo, por ser um método mais simples e apropriado para o nosso estudo. A aplicação dos questionários aconteceu entre os meses de fevereiro e março de 2011. Os dados foram tabulados e analisados.

\subsection{RESULTADOS}

Após a tabulação dos dados sobre a percepção ambiental dos ribeirinhos foi realizada junção dos seus resultados com os conhecimentos científicos adquiridos em vários artigos científicos. Segundo FAGGIONATO (2002) a percepção ambiental dos indivíduos pode ser obtida a partir de questionários, e foi por meio dessa ferramenta que obtivemos os dados da pesquisa. 


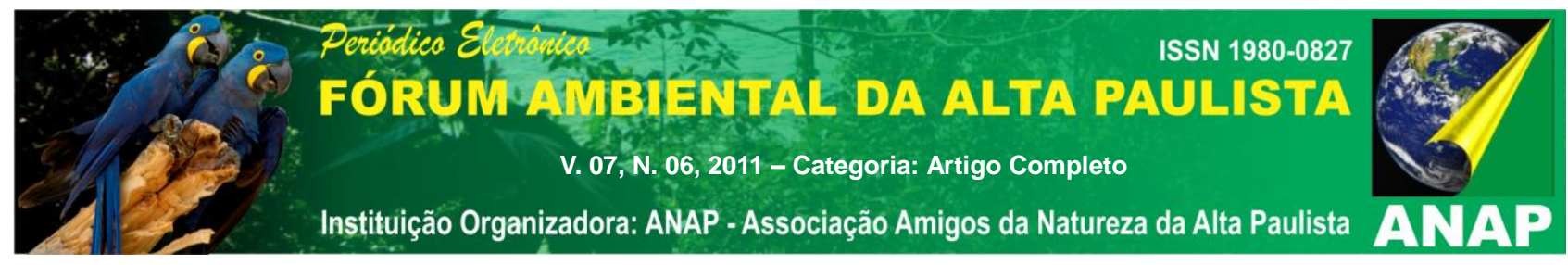

Dos ribeirinhos entrevistados $58,1 \%$ são do sexo feminino e $41,9 \%$ do sexo masculino, com níveis de escolaridade bem diversificado, porem a maior porcentagem, 31,4\%, tem nível médio completo, 25,7\% fundamental incompleto, e 14,3\% dos ribeirinhos não foram alfabetizados, uma quantidade considerável, a baixa escolaridade da população dificultou a coleta dos dados, com relação às respostas dos moradores, muitos não entenderam algumas questões que foram apresentadas, sendo necessário serem bem explicadas pelos entrevistadores. Sendo que os mesmos tiveram cuidado em não influenciar nas respostas dos entrevistados.

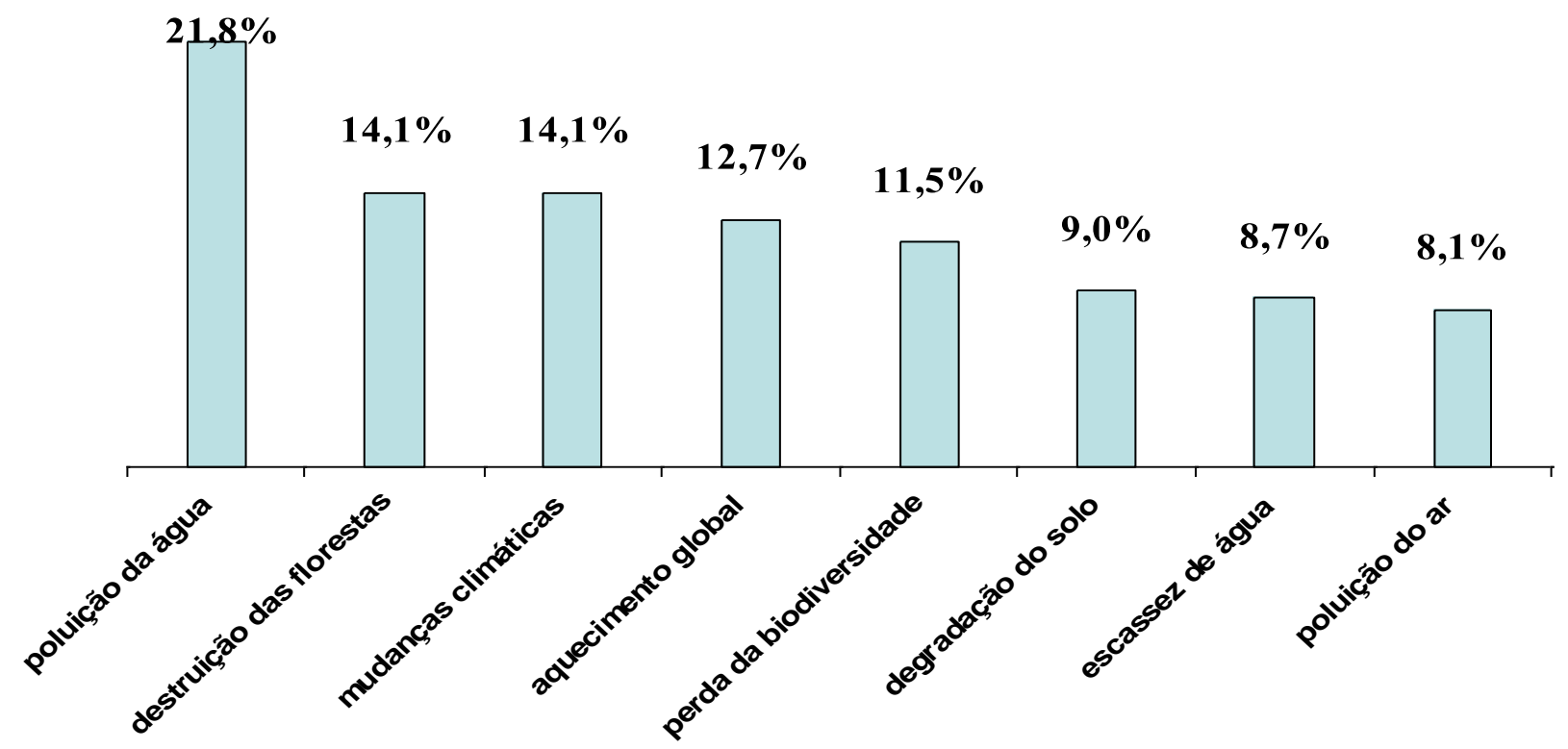

Gráfico 01: Problemas ambientais que mais afetam os ribeirinhos.

Os problemas ambientais tais como poluição da água, destruição das florestas, mudanças climáticas, aquecimento global, entre outros, estão interligados, e os moradores já se sentem afetados pelos mesmos (gráfico 01), principalmente poluição da água com 21,8\%, destruição das florestas 14,1\% e mudanças climáticas 14,1\%, e 15,9\% dos entrevistados afirmaram que o maior problema para as próximas gerações é a poluição da água, pois já é notório que a água do rio está perdendo sua qualidade devido o manejo inadequado dessa bacia, em outro questionamento sobre a possibilidade da 


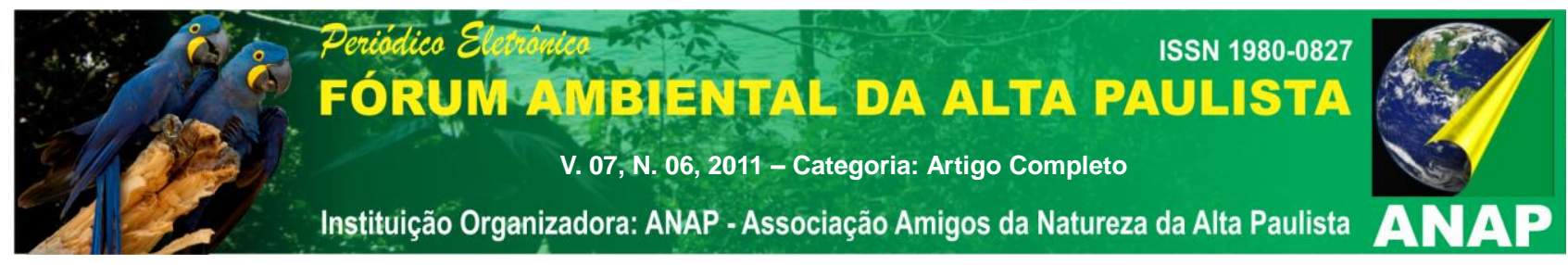

água vir a faltar na região, $54 \%$ da população entrevistada acreditam que pode ocorrer esse fato na localidade. Constatou-se que os moradores estão bastante preocupados com o futuro, pois eles precisam do recurso hídrico para a sobrevivência das próximas gerações.

Quando os ribeirinhos foram questionados sobre a importância do rio para a comunidade, 98,2\% afirmaram que o rio tem muita importância, 0,9\% pouca importância e 0,9\% dos moradores disseram ser o rio sem importância. Os moradores não têm conhecimento elevado sobre como preservar um recurso hídrico, sentem que o rio é importante e que é necessário cuidados, apenas $28,6 \%$ dizem conhecer bem como preservar, 57,1\% conhecem razoavelmente, $10,5 \%$ não conhece nada e 3,8\% está procurando conhecer mais sobre a temática.

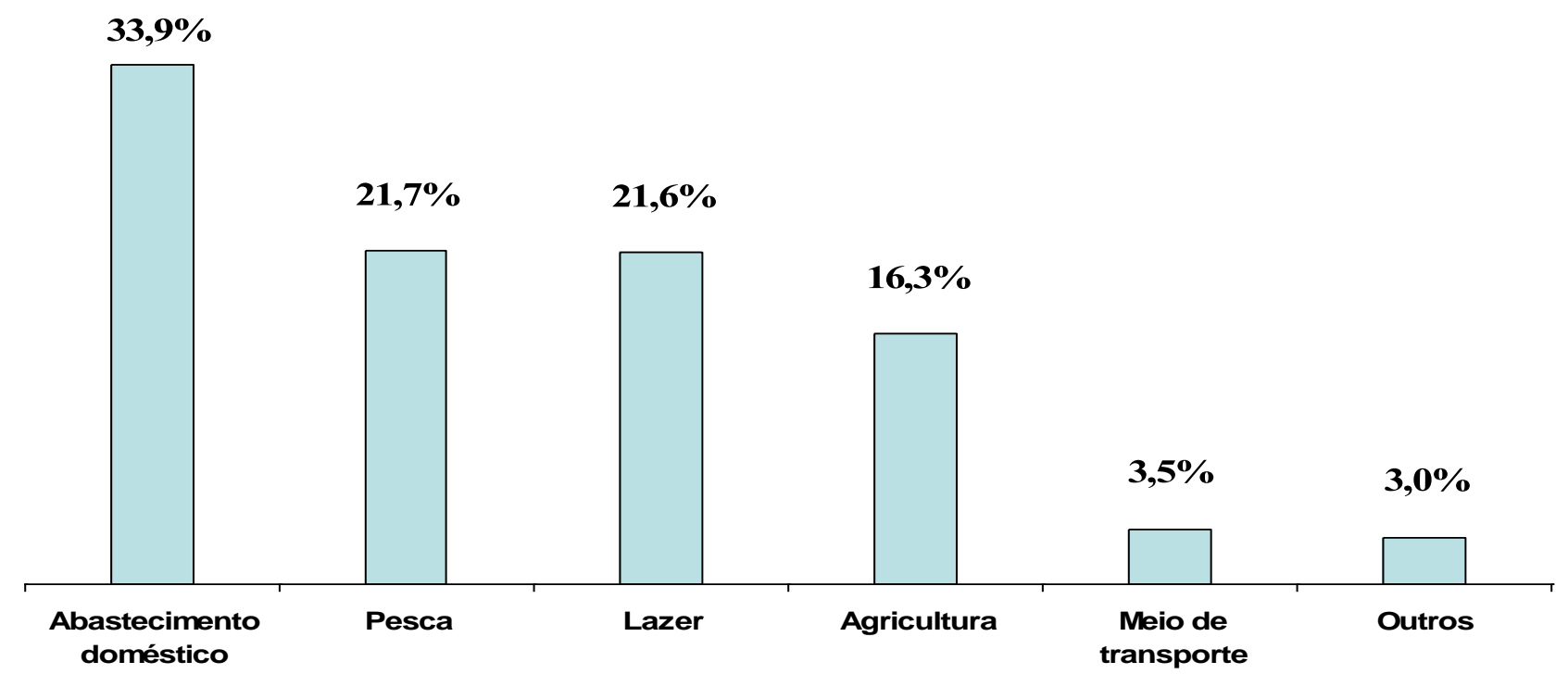

Gráfico 02: Importância do rio Taquari para os ribeirinhos.

Em outro questionamento sobre as atividades mais importantes desenvolvidas às margens do rio (gráfico 02), 33,9\% responderam abastecimento doméstico, 21,7\% pesca, $21,6 \%$ lazer, $16,3 \%$ agricultura, 3,5\% meio de transporte e 3\% outros. O rio Taquari é de fundamental importância para o desenvolvimento da cidade, sua água é utilizada para o abastecimento doméstico principalmente, irrigação, uso industrial (cerâmica), agricultura, 


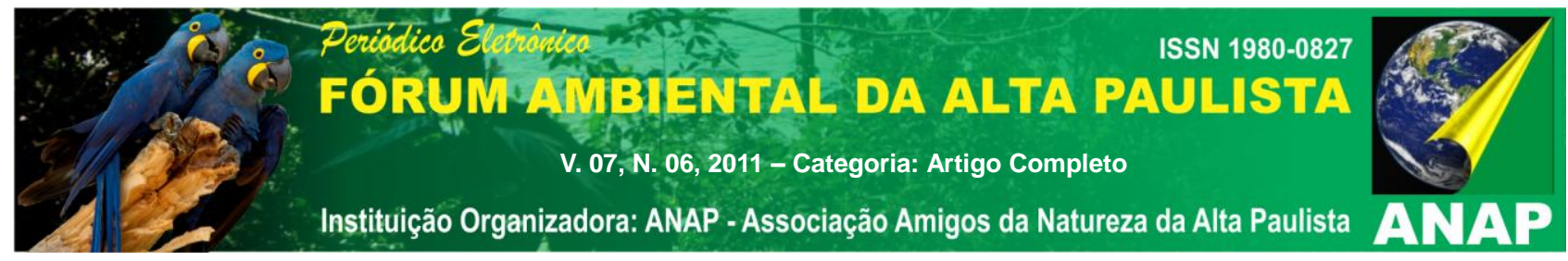

lazer, entre outras.

A grande maioria da população, 86,7\%, afirmou que não considera as margens do rio Taquari preservada e apenas $13,3 \%$ declaram que as margens são preservadas. A dependência que a comunidade tem com o rio é inquestionável, contudo apenas 68,6\% da população declarou realizar ações que contribuem para sua preservação.

$\mathrm{Na}$ área urbana observamos que pela aglomeração de pessoas há uma imensa degradação nas margens do rio, sua extensão no território urbano está bastante comprometida, por que grande parte da mata ciliar foi destruída pela ação humana, sendo que muitas famílias têm o quintal de suas casas com acesso para o rio, alguns jogam lixo doméstico, usam o recurso para lavar automóveis, nas propriedades rurais localizadas na área urbana muitos ribeirinhos desmatam as margens para produção de pastagens, entre outros impactos.

Alguns moradores estão preocupados com a rapidez do assoreamento e a degradação em todos os aspectos, muitos no momento da entrevista demostraram preocupação com o futuro desse recurso que consideram de imensa importância para 0 município e interesse em sua recuperação e conservação, percebem o problema como sendo deles, principalmente por que o rio é a fonte de captação de água para o abastecimento do município.

Antigamente, muitos consideravam o recurso inesgotável, e por isso não cuidavam de forma adequada e racional por falta de conhecimento sobre o recurso hídrico. A maioria dos entrevistados não consideram mais o Taquari como um rio e sim como um córrego, devido a diminuição do volume de água do mesmo. No território urbano as margens perderam suas características naturais. Assim como na maioria dos rios que atravessam as cidades brasileiras, o rio Taquari é considerado um grave problema ambiental, pois infelizmente a população não tem cuidado de forma adequada, fazendo do recurso hídrico depósito de lixo e esgoto doméstico.

Os resultados de todos estes impactos são severos para as populações humanas, pois afeta todos os aspectos da vida diária das pessoas, a economia regional e nacional e a saúde humana. $E$ têm conseqüências que podem ser resumidas em: degradação da qualidade da água superficial e subterrânea, aumento das doenças 


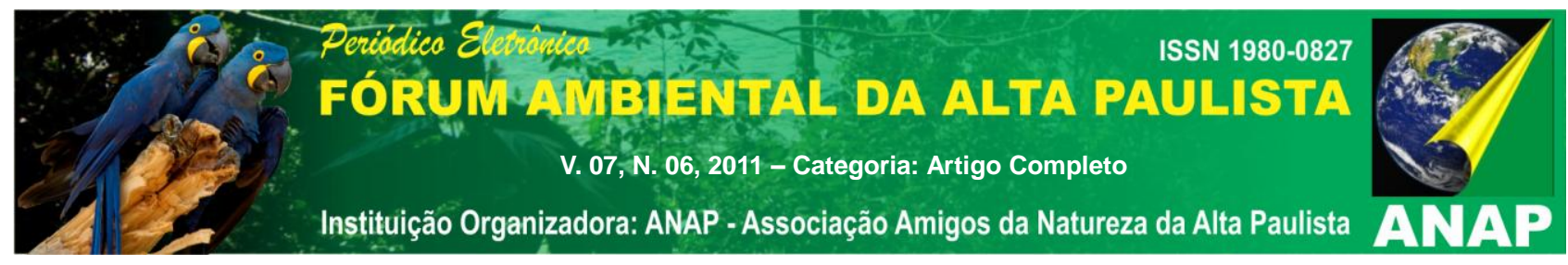

de veiculação hídrica e impactos na saúde humana, diminuição da água disponível per capita, aumento no custo da produção de alimentos, impedimento o desenvolvimento industrial e agrícola e com prometimento dos usos múltiplos e aumento dos custos de tratamento de água (Tundisi, 2003).

Desde o primeiro contado como os moradores ribeirinhos percebemos que os mesmos compreenderam a necessidade de uma reflexão sobre a problemática ambiental que estão inseridos, que o município necessita de políticas públicas para gestão e manejo ambiental, subsídios que venham contribuir para ações concretas de proteção, conservação e manutenção dos recursos hídricos, e um programa de educação ambiental no município, pois a população de Araguatins anseia por mais informações sobre a temática.

\section{CONCLUSÃO}

Percebemos que a maioria dos ribeirinhos começaram a entender a complexidade de uma bacia hidrográfica, a utilidade desse recurso para a sobrevivência humana e de outros organismos vivos, o que acontece ao rio Taquari pode afetar vários aspectos da vida humana, como a economia regional e a saúde humana. Em suas respostas ficou bem que os mesmos sabem que o mundo está sendo afetado por problemas como: poluição da água e do ar, degradação do solo, destruição das florestas, escassez de água, perda de biodiversidade, mudanças climáticas, aquecimento global, entre outros.

Os problemas ambientais são importantes e devem ser discutidos, principalmente em um ambiente em que as pessoas enxergam e sentem esses problemas como sendo delas. Os ribeirinhos sofrem com os efeitos da degradação ambiental, eles não têm a menor idéia das relações entre diversidade dos ecossistemas e o desenvolvimento sustentado, eles possuem,no entanto, uma vivência direta e dramática com as piores manifestações de poluição e de agressões ambientais.

A maioria não exercita a prática de conservação do meio ambiente por falta de conhecimento acerca da temática. Foi constatado que, o contato com a realidade deles, 


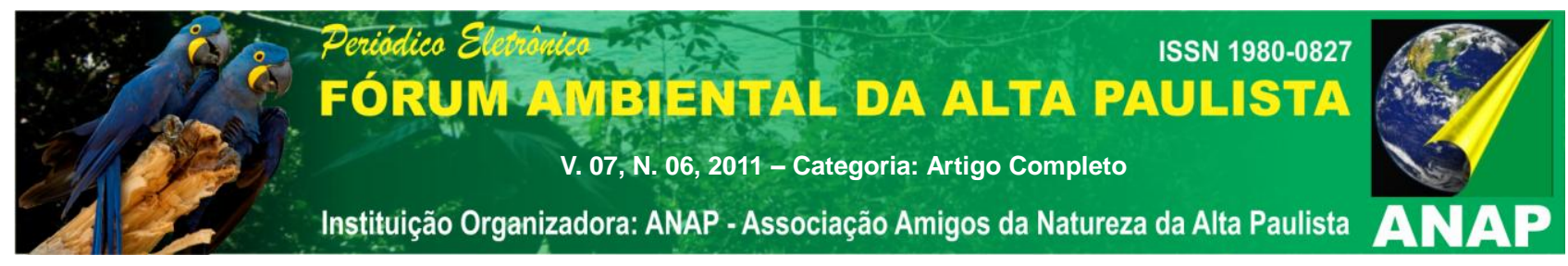

contribuiu para a reconstrução de conhecimentos, possibilitando a reflexão sobre o meio que estão inseridos e a percepção de novos valores diante da relação ser humano/ambiente.

Espera-se que com as informações obtidas possam ser implementados programas de educação ambiental que permitam melhor conscientização da população, contribuindo para a conservação do recurso hídrico que é imprescindível para as comunidades biológicas'locais.

\section{REFERÊNCIAS}

CARVALHO, Aurean de P. et al. Diagnóstico da Degradação ambiental da Bacia do Rio Taquari em Araguatins (TO). Revista Caminhos de Geografia. V.7, n. 20, p. 113 129. Fev. 2010.

CARVALHO, J. B. Percepção e relações ambientais de moradores da comunidade agrícola Palestina no município de Axixá-TO : Percepção ambiental. Monografia (pós graduação lato sensu em Gestão e Manejo Ambiental em Sistemas Agrícolas) Universidade Federal de Lavras, Minas Gerais, 2007.

FAGGIONATO, Sandra. Percepção Ambiental. Disponível em: <www.educar.sc.usp.br/biologia/textos> Acessado em: 03/03/2011.

FERNANDES, R. S., et al. Uso da Percepção Ambiental como instrumento de gestão em aplicações ligadas às áreas educacional, social e ambiental. Disponível em: < http:// www.redeceas.esalq.usp.br/noticias/percepcao ambiental.pdf $>$. Acesso em 17 de jan de 2011.

HOUSE, M. A. Citizen participation in water management. Water Science Technology. V. 40. N.10. p. 125 - 130. 1999. 


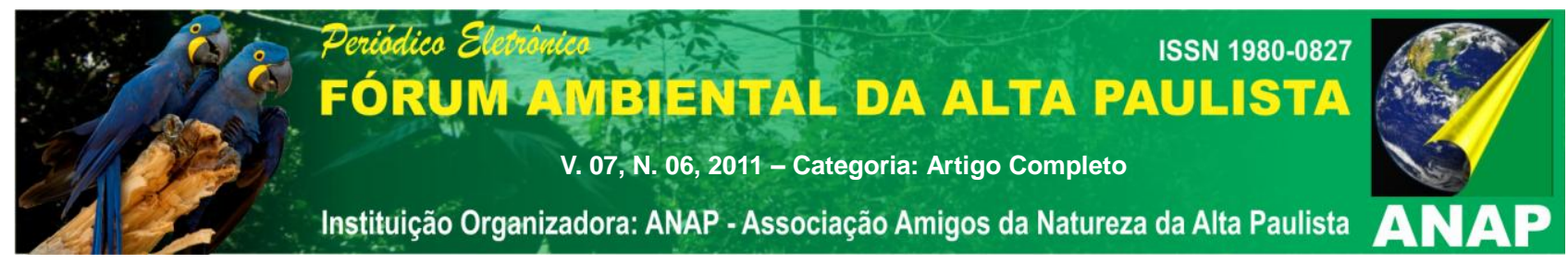

MACEDO, Renato Luiz Grisi. Percepção e Conscientização Ambiental. Lavras/MG:

Editora UFLA/FAEPE. 2000.132p.

STRANZ, A. et al. Projeto Universidade Solidária - Transmitindo Experiências em Educação Ambiental. In: ZAKRZEVSKI, Sônia B. B. ,VALDUGA, Alice T. ,DEVILLA, Ivano A.(orgs). Anais do I Simpósio Sul Brasileiro de Educação Ambiental, II Simpósio Gaúcho de Educação Ambiental, XVI Semana Alto Uruguai do Meio Ambiente. Ed. EdiFAPES. Erechim - RS. P. 222. 2002.

TUNDISI, J.G. Água no século XXI: enfrentando a escassez. São Carlos, Editora Rima, IIE, 2003. 